\title{
Participatory disease surveillance of transboundary animal diseases in Gboko, konshisha and Katsina Ala Local Government areas of Benue State, Nigeria
}

Ndumari Wachida ${ }^{1 *}$, Terzungwe Tughgba ${ }^{1}$ and Paul Hambesha ${ }^{2}$

*Correspondence: ndumariwachida@gmail.com

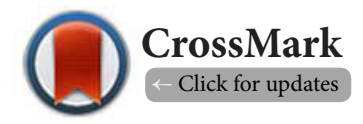

\begin{abstract}
'Department of Surgery and Theriogenology, College of Veterinary Medicine, University of Agriculture P.M.B 2373 Makurdi, Benue State, Nigeria.

${ }^{2}$ Veterinary Teaching Hospital, University of Agriculture P.M.B 2373 Makurdi, Benue State, Nigeria.
\end{abstract}

\begin{abstract}
Transboundary animal diseases are diseases that are highly infectious and have serious economic impact on livestock farmers and the economy. These diseases also affect the international trade, food security and food safety of the nation. Prevalence of various important livestock diseases particularly the Transboundary Animal Diseases (TADs) in Gboko, Konshisha and Katsina Ala LGA areas of Benue State were determined by applying different tools of Participatory Disease Surveillance (PDS). Analysis of data indicated that Peste des petits ruminats (PPR), African swine fever (ASF), Newcastle disease (ND) and Foot and mouth disease (FMD) were the most important and prevalent livestock diseases in these areas. Participatory disease surveillance proved to be a useful tool to collect reliable data that can be utilized by the policy makers for the control/eradication of animal diseases in Nigeria.
\end{abstract}

Keywords: Transboundary animal diseases (TADs), Participatory disease surveillance (PDS), Rinderpest, (RP) Highly pathogenic avian influenza (HPAI)

\section{Introduction}

Participatory epidemiology (PE) is the use of participatory approaches and methods to improve our understanding of the patterns of diseases in populations. These approaches and methods are derived from participatory appraisal. The empowerment of people to find solutions to their own development and challenges is called Participation [1]. Participatory appraisal (PA) is a family approaches and method that enable people to present, share and analyze their knowledge of life and conditions to plan and to act on them. It is participatory, flexible, lightly structured, adaptable, exploratory, empowering and inventive. Types of participatory appraisal include rapid rural appraisal, participatory rural appraisal (PRA), farming systems research and participatory impact assessment [1]. Participatory Disease Surveillance (PDS) is the application of PE to disease surveillance. PDS is a method of disease surveillance where PA approaches and methods are used to combine local veterinary knowledge with conventional methods to establish the presence or absence of a specific disease in a particular area [1]. PE is based on communication and transfer of knowledge using a variety of methods. There are three main groups involve in this methods, (a) Informal interviewing which includes semi-structured interviews with key informants, focus-group discussions or individual livestock keepers, (b) ranking and scoring which comprises of simple ranking, pairwise ranking, proportional piling and matrix scoring and (c) visualization which comprises of mapping, timelines, seasonal calendars and transect walks. These are complemented by Secondary information sources obtained before going to the study area and as the study is conducted, direct observation of animals, farms, villages were carried out, while in the study area Laboratory diagnostics if available, field diagnostic tests are used, complemented by sample collection and testing by a regional or national laboratory for confirmation. Data are crosschecked by probing, triangulation and laboratory diagnosis [2-4]. Participatory Epidemiology relies on the widely accepted techniques of participatory rural appraisal, ethno-veterinary surveys and qualitative epidemiology [5]. This information can 
Wachida et al. Epidemiology Reports 2017,

be used to design better animal health projects and delivery systems, more successful surveillance and control strategies or as new perspectives for innovative research hypotheses in ecological epidemiology [6].

In February 2006, Nigeria became the first country in Africa to report the presence of Highly Pathogenic Avian Influenza (HPAI). Within months, the spread became very noticeable and by September 2008, 25 out of the 36 states of the federation had reported the disease in poultry with only one confirmed fatal human case. Many states including the Federal Capital Territory have so far been affected [7].

The failure of formal data-collection methods to produce cost-effective and reliable information for designing rural development projects in developing countries was first recognized in the early 1970 s [8]. This problem was related to the behavior and methods used by researcher which limited their capacity to understand the problems of the poorest and most marginalized people in rural communities. In response to this situation, alternative systems of inquiry have since been developed. These systems include rapid rural appraisal (RRA) and participatory rural appraisal (PRA) which, to varying degrees, enable local people to play a more active role in defining, analyzing and solving their own problems [8].

This study was conducted in order to establish the presence or absence of TAD. And to establish data that will be useful for planning the prevention and control of TADs in these areas of study.

\section{Materials and methods PDS Team}

The team consisted of five veterinarians working together as facilitator, tool applicator, recorder, observer and photographer during field activities.

\section{Selection of villages}

A total of 23 villages were randomly selected from South, West, East, North and central of Gboko, Konshisha and Katsina Ala LGA areas for dispersion of coverage.

\section{Arrangement of meetings/interviews}

Interviews for the exercise were organized with the assistance of local Veterinary Officer/Veterinary Assistant, in each village according to the suitability of time, place, local politics, conflicts and weather for the farmers. Efforts were made to include farmers of all age groups and subsequently, interviews were conducted with the aid of a check list which includes introduction of the team and respondents, livelihood/activities, type of animal kept, production systems, constraints, disease problem, local name of disease and their clinical signs, treatment, question and advice. Materials that were used for the purpose of this study include Geographical Positioning System (GPS, GARMIN'seTrex Legend personal navigator), cardboard papers, permanent markers, digital camera, counters, pictures of sick animals showing various symptoms. Other tools that were used were scoring and ranking (proportional pilling) and Visualization (includes mapping, seasonal calendar and transect walk).

In order to avoid bias, the Participatory Disease Surveillance (PDS) Team did not mention about transboundary animal diseases (TADs) during interview prior to the introduction of the subject by the respondents a check list was designed, for interview with key informants to collect information about important diseases of livestock in the areas of study and information obtained were recorded.

\section{Data analysis}

Data was analyzed as indicated in "A Manual for Participatory Disease Surveillance Practitioners: Introduction to participatory epidemiology and its application to highly pathogenic avian influenza participatory disease surveillance" and presented as bar chart.

\section{Result \\ Local perceptions of disease recognition}

First task of PDS team was to clearly understand Local (Traditional) names and clinical signs of important livestock diseases as mentioned by the farmers. Use of pictures of sick animals showing various symptoms was quite helpful and use of local name of different diseases encouraged the farmers to explain health problems of animals in a better way. Although in Gboko, Konshisha and Katsina Ala LGA areas about $65 \%$ farmers are not educated and have poor knowledge particularly about Rinderpest and Avian influenza, the awareness about peste des petits ruminants (PPR), African swine fever and foot and mouth disease were very high.

Table 1 show the list of 23 villages and their GPS location in Gboko, Konshisha and Katsina Ala LGA areas of Benue State were participatory disease surveillance was carried out.

Based on simple ranking, the most abundant livestock specie in the 23 villages in the three local government areas (LGA) where this study was conducted were Goats, pigs and poultry, followed by cattle, sheep, fish and Rabbit respectively (Figure 1).

Table 2 indicates the various diseases of livestock encountered by the farmers in the 23 villages/communities where this study was done. Result indicates PPR as the most common disease of goats followed by mange, helminthosis, lousiness and mastitis respectively. Poultry is most affected by ND in these regions, followed by, CRD, fowl pox, Coccidiosis and helminthosis. Ranked first among the diseases of pigs are ASF, mange, lousiness and helminthosis. Finally, cattle are most affected by FMD, then CBPP, helminthosis, mange and mastitis Result of proportional piling ranking the most important livestock diseases as determined by the livestock farmers in Gboko, Konshisha and Katsina Ala LGA areas of Benue State (Figures 2-5).

Figure 6 . Show the seasonal prevalence of the main livestock disease in the three Local Government areas where this 
Wachida et al. Epidemiology Reports 2017,

Table 1. List of villages and their location in Gboko, Konshisha and Katsina Ala LGA Benue State.

\begin{tabular}{llll}
\hline S/Number & Villages & Latitude N & Longitude E \\
\hline 1 & Genyi & 07.36302 & 009.04538 \\
2 & Gboko East & 07.32676 & 009.00590 \\
3 & Gboko South & 07.30544 & 009.01344 \\
4 & Gboko West & 07.31213 & 008.98835 \\
5 & Mbakyambe & 07.34093 & 009.08410 \\
6 & Mbanev & 07.30844 & 009.04761 \\
7 & MbaakomIpav & 07.32777 & 009.03394 \\
8 & Mbayion & 07.28504 & 008.98431 \\
9 & Gboko North & 07.35870 & 009.00914 \\
10 & Ikowe & 07.22331 & 009.36330 \\
11 & Gosema & 07.18510 & 009.31903 \\
12 & Karmem & 07.16373 & 009.35345 \\
13 & Sati-Agirigi & 07.16081 & 009.33513 \\
14 & Tomataan & 07.15271 & 009.29915 \\
15 & Tormkar & 07.29446 & 008.55018 \\
16 & Ugambe & 07.22785 & 008.49307 \\
17 & Gbinde & 07.08494 & 008.49307 \\
18 & Gugughul & 07.14174 & 008.57727 \\
19 & Tse-Abberagba East & 07.07757 & 008.67183 \\
20 & Jovmbavaa & 06.82374 & 008.99248 \\
21 & Mbaamo-Tongo & 06.82374 & 008.99248 \\
22 & Gboraya & 07.18049 & 009.28451 \\
23 & Azege & 07.18049 & 009.28520 \\
\hline & & & \\
\hline & & & \\
13 & & &
\end{tabular}

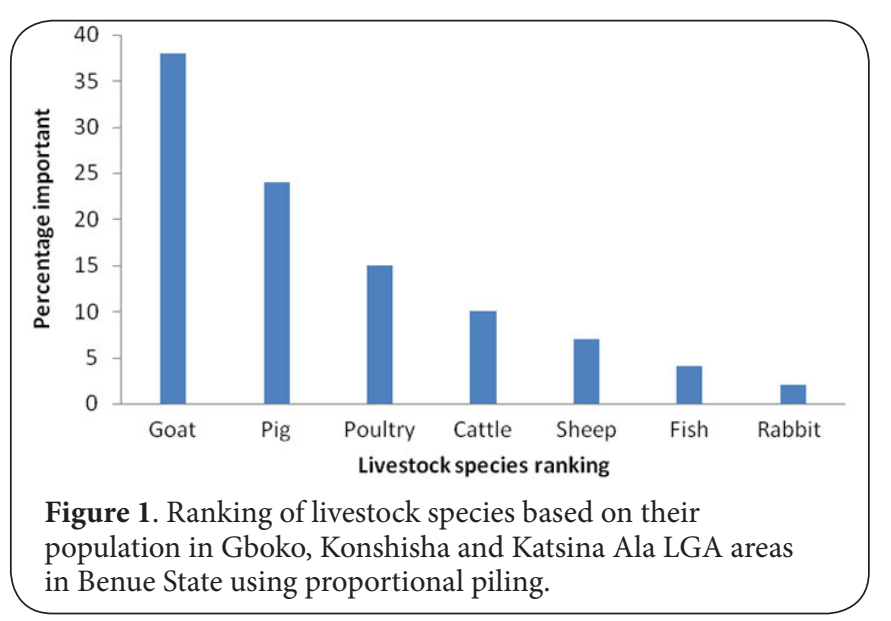

study was carried out as determined by the livestock farmers using proportional piling. Result indicates that PPR in goat, ND in poultry, ASF in pig and others were highly prevalent in raining season. FMD in cattle is prevalence all year round.

\section{Discussion}

Results of PDS activity performed in Gboko, Konshisha and
Table 2. Diseases of livestock, Traditional and English names in Gboko, Konshisha and Katsina Ala LGA areas of Benue State.

\begin{tabular}{ll}
\hline $\begin{array}{l}\text { Traditional(Tiv dialet) } \\
\text { name of diseases }\end{array}$ & $\begin{array}{l}\text { English name } \\
\text { of diseases }\end{array}$ \\
\hline (a) Goat & \\
\hline Anule & PPR \\
Lagh & Mange \\
Anyigol & Helminthosis \\
Paregh & Lousiness \\
Kpesekombo & Mastitis \\
\hline (b) Poultry & \\
\hline Amua & ND \\
Hough & CRD \\
Azough & Fowl pox \\
Nyiawambe & Coccidiosis \\
Anyigol & Helminthosis \\
\hline (c) Pig & \\
\hline Anule & ASF \\
Lagh & Mange \\
Paregh & Lousiness \\
Anyigol & Helminthosis \\
\hline (d) Cattle & \\
\hline & FMD \\
Hough & CBPP \\
Anyigol & Helminthosis \\
Lagh & Mange \\
Kpesekombo & Mastitis \\
\hline
\end{tabular}

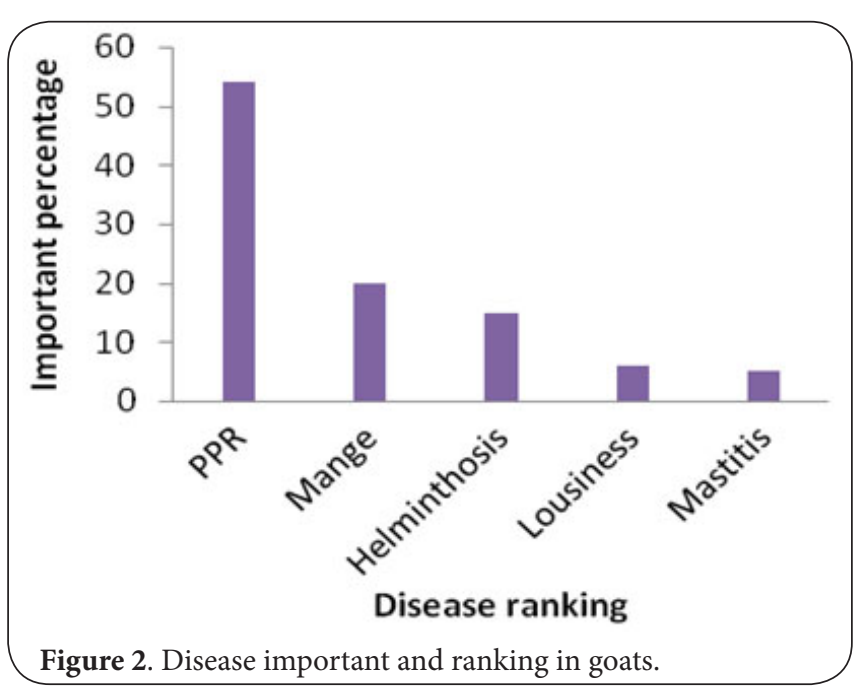

Katsina Ala Local Government areas disclosed that there is no history of Highly Pathogenic avian influenza (HPAl) and Rinderpest Foot and mouth diseases (FMD), PPR and ASF are prevalent in the areas.

From this study goats were found to be the most populated animal species among the livestock in these areas, probably because of it prolificacy that bring quick financial return and 

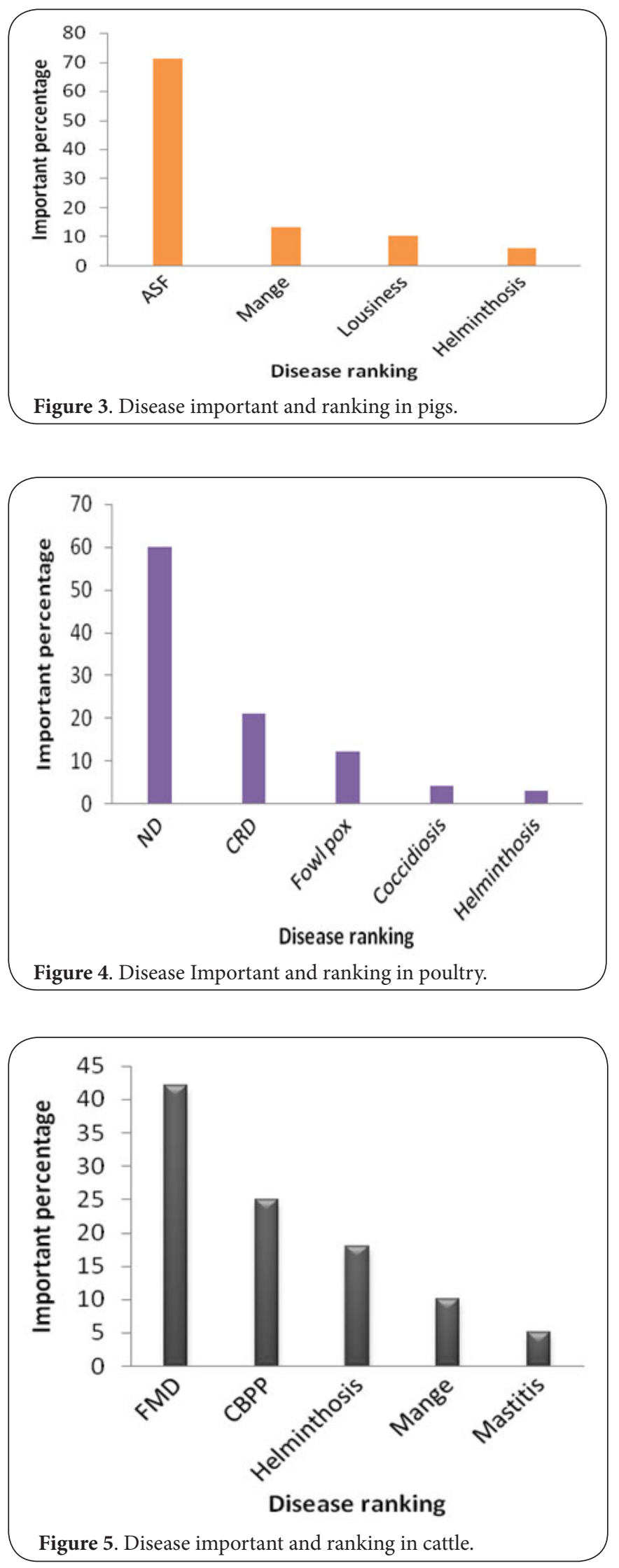

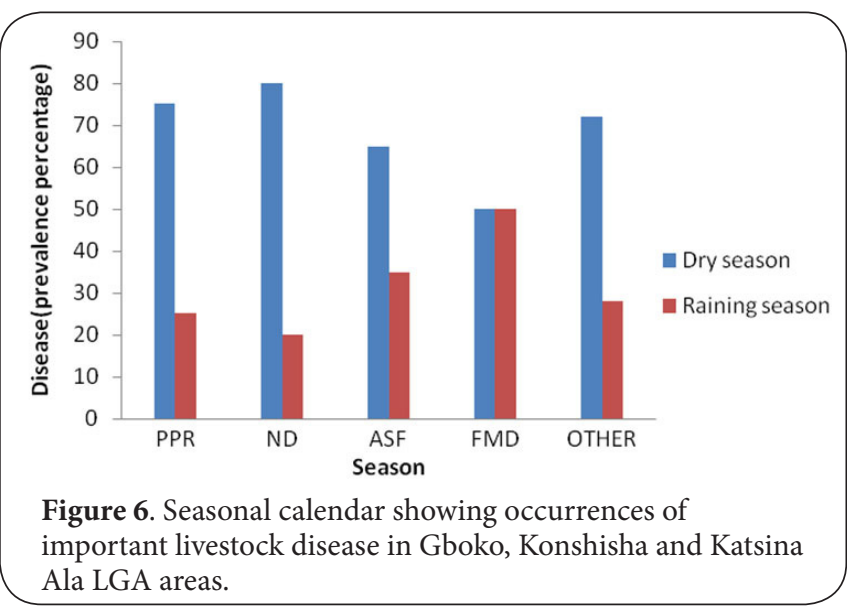

cultural values attached to them in the area. However, they are confronted with various diseases among which PPR is the most important because of its very high morbidity, mortality and case fatality rates that cause adverse effect on the livelihood of these farmers. This study tallies with the studies of [9] and [10] where PPR was the most important disease of sheep and goats in Plateau and Borno states respectively. From the finding of this study, using seasonal calendar, this disease can be controlled by annual PPR vaccination from month of September, October before the onset of the disease outbreak which normally occurs in October. Other diseases of goat in the areas are mange, helminthosis, lousiness and mastitis that can be control by good health management.

Pigs was found to be the second most abundant after goats in the areas of study. But was discouraged by frequent out breaks of ASF due to the economic impact faced by the livestock farmers during outbreaks. There also suffer from other diseases like mange, lousiness and helminthosis that can be manage by proper health care the studies of [9] revealed ASF as one of the diseases that affect pigs in plateau state even though it was not the most important.

Poultry happen to be the third animal species reared by the livestock farmers in these areas. New Castle Disease (ND) is the most important disease that affects chickens in this part of the country resulting in very high morbidity, mortality and case fatality rates, other diseases are chronic respiratory disease (CRD), coccidiosis, fowl pox and Helminthosis. Other related studies also confirms ND as the most important disease of poultry in various parts of the country, this include studies by [10-12] Based on this study we recommend the strict adherence to ND routine vaccination so as to tackle the problem.

Also, fowl pox vaccination could be carried out to prevent further occurrence of the disease. Antihelminthics could be given before the onset of raining season and during raining season.

Foot and Mouth Disease (FMD) is the most important disease of cattle in this area and is also a transboundary animal disease of cattle. Similar studies were conducted in Borno 
state by [10] and Plateau states by [9] which also revealed FMD as the most common disease of cattle in these areas. Our study also tallies with the findings of [6] and [13] the studies were conducted in Paskistan which rated FMD as the most prevalent disease of cattle in Islamabad Capital Territory and Karachi District.

In addition to the data that emerged during Participatory research, the process of sitting and listening to the people had value in itself. This exercise took the form of providing people an opportunity to express their views and helped to improve the community's relationship with the researchers. We observed that the methods applied in the field were valuable for understanding local description of animal diseases, estimating disease prevalence, importance and analyzing seasonal pattern of animal diseases. In the beginning, farmers were reluctant to share their information and hesitated to take active part in group discussion. However, once they realized the purpose of the meeting and importance of their indigenous knowledge, it was very convenient to extract information prevailing in the area. In these three local government areas livestock farmers are confronted with the challenges of capital, housing, livestock feed and availability of Veterinary services.

\section{Conclusion}

The transboundary animal diseases that are prevalent in Benue State from our studies are ND, PPR, FMD and ASF. This finding happens to be similar to various PDS conducted around the nation. There is need to tackle the problem of these TADs which seems to have serious socio-economic impact and is also a treat to international trade, food safety and food security of the nation. Participatory Disease surveillance as a tool has proved to be viable in this study and we strongly recommend the use of PDS in outbreak investigations.

\section{Competing interests}

The authors declare that they have no competing interests.

Authors' contributions

\begin{tabular}{|l|c|c|c|}
\hline Authors' contributions & NW & TT & PH \\
\hline Research concept and design & -- & $\checkmark$ & -- \\
\hline Collection and/or assembly of data & -- & $\checkmark$ & -- \\
\hline Data analysis and interpretation & -- & $\checkmark$ & -- \\
\hline Writing the article & -- & $\checkmark$ & -- \\
\hline Critical revision of the article & -- & $\checkmark$ & -- \\
\hline Final approval of article & -- & $\checkmark$ & -- \\
\hline Statistical analysis & -- & $\checkmark$ & -- \\
\hline
\end{tabular}

\section{Acknowledgement}

Federal Ministry of Agriculture and Rural Development, Nigeria. The project was sponsored by the "Early Detection, Reporting and Surveillance of Avian Influenza for Africa (EDRSAIA)" in collaboration with International Livestock Research Institute (ILRI). Authors of this report are highly thankful to the Project Management for providing all technical and financial support for the completion of this assignment.

\section{Publication history}

Editor: Nicola Luigi Bagazzi, University of Genoa, Italy. Received: 06-Apr-2017 Final Revised: 31-Jul-2017

Accepted: 07-Sep-2017 Published: 14-Sep-2017

\section{References}

1. International Livestock Research Institute (ILRI). A Manual for participatory disease surveillance practitioners: Introduction to participatory epidemiology and its application to highly pathogenic avian influenza participatory disease surveillance. 2009; 1-56.

2. Pretty N.J, Guijt I. Thompson J and Scoones I. Participatory learning and action: A trainer's guide. IIED participatory methodology series. IIED (International Institute for Environment and Development), London, UK. 1995; 9.

3. Mariner J.C and Paskin R. Manual on participatory epidemiology: Methods for the collection of action oriented epidemiological intelligence. FAO Animal Health Manual. 2000.

4. Catley A. Participatory epidemiology: A guide for trainers. African Union - Interafrican Bureau for Animal Resources, Nairobi. 3. Chambers R. 1983.

5. Schwabe C.W. Veterinary Medicine and Human Health. Williams \& Wilkins, Baltimore. 1984; 680.

6. Manzoor H M. Amjad Malik, Zahida Fatima M and Rizwan Yousuf. Participatory Surveillance of Livestock Diseases in Islamabad Capital Territory. Int. J. Agri. Biol. 2005; 7:567-570.

7. Bird Flu Watch. A Publication of Nigeria's Avian Influenza Control and Pandemic Preparedness and Response Project (AICP). 2009; 1:1-8.

8. Chambers R. The Origins and Practice of Participatory Rural Appraisal. World Dev. RRA Notes. 1994; 20:115-23. I Article

9. Ndahi M.D, Kwaghe A.V, Usman J.G, Anzaku S, Bulus A and Angbashim J. Detection of transboundary animal diseases using participatory disease surveillance in Plateau state, Nigeria. World Rural Observations. 2012; 4:71-77. | Article

10. Geidam Y.A, Kwaghe A.V, Umar I, Sunday J, Musa D, Bukar G and Ndahi M.D. Participatory Disease Surveillance in the Detection of Transboundary Animal diseases (TADs) in Borno State of Arid North-eastern Nigeria.Bulletin of Animal Health and Production in Africa. 2013; 61:231239. | Article

11. Ndahi M.D and Kwaghe A.V. Participatory disease surveillance of hipathogenic avian influenza in Mangu local government area of Plateau state, Nigeria. Researcher. 2011; 3:8-14. I Website

12. Kwaghe A.V, Ndahi M.D, Usman J.G, Sambo E, Waziri I, El-Oji A.A, Pam E.G, Jost C.C, Acho I.O and Tchangai C.P. Highly pathogenic avian influenza participatory disease surveillance in Plateau state, Nigeria. Archives des Sciences. 2012; 65:132-142. | Pdf

13. S. Noman Ali, Manzoor Asif, Attique Reshman, Liaquet Alitat, Ali and Manzoor Hussain. Participatory surveillance of livestock diseases in District Karachi- Pakistan. In. j. Agri. Biol. 2006; 8:653-656.

Citation:

Wachida N, Tughgba T and Hambesha P.

Participatory disease surveillance of transboundary animal diseases in Gboko, konshisha and Katsina Ala Local Government areas of Benue State, Nigeria. Epidemiol Rep. 2017; 5:1.

http://dx.doi.org/10.7243/2054-9911-5-1 